\title{
Glycemic control and health behaviors in adolescents with type 1 diabetes
}

\author{
Aylin Yetim ${ }^{1}$ Müjgan Alikaşifoğlu², Firdevs Baş², Kayı Eliaçık², Gülnaz Çı̆̆ ${ }^{4}$, \\ Ethem Erginöz ${ }^{4}$, Oya Ercan ${ }^{5}$, Rüveyde Bundak ${ }^{3}$ \\ ${ }^{1}$ Division of Adolescent Medicine, Department of Pediatrics, ${ }^{3}$ Division of Pediatric Endocrinology and Diabetes, Istanbul \\ School of Medicine, Istanbul University, ${ }^{2}$ Division of Adolescent Medicine, Department of Pediatrics, ${ }^{4}$ Department of Public \\ Health, ${ }^{5}$ Pediatric Endocrinology and Diabetes, Cerrahpaşa School of Medicine, Istanbul University, Istanbul, Turkey. \\ E-mail: drkasif.m@gmail.com
}

Received: 18th July 2017, Revised: 9th September 2017, Accepted: 27th November 2017

SUMMARY: Yetim A, Alikaşifoğlu M, Baş F, Eliaçık K, Çı̆̆ G, Erginöz E, Ercan O, Bundak R. Glycemic control and health behaviors in adolescents with type 1 diabetes. Turk J Pediatr 2018; 60: 244-254.

The purpose of this study was to determine the health/health risk behaviors of a group of Turkish adolescents with type 1 diabetes (T1D) to determine the prevalence and explore the exact effect of these behaviors on glycemic control (GC). A total of 210 adolescents (age 12-20 years; diabetes duration $>6$ months; no additional comorbidities), completed a self-administered questionnaire (including some questions from Health Behavior in Schoolaged Children study questionnaire). Subjects were divided into two groups based on the hemoglobin A1c (HbA1c) levels, measured in the last 3 months: good GC (HbAlc $<8 \%$ ) and poor GC (HbAc1 $\geq 8 \%)$. Chi-square tests and backward stepwise logistic regression analysis were used in statistical analyses. Of the patients, 57 had good GC and 153 had poor GC. The results of the backward stepwise logistic regression analysis indicated that being overweight and frequent electronic media use were risk factors for poor GC, whereas computer use for homework for long period of time ( $\geq 2$ hours/day) was found to be a protective factor in terms of GC. Screening adolescents in terms of health/health risk behaviors such as frequent electronic media use, and giving adolescents health responsibilities should be an integral part of the follow-up of these patients, and intervention programs that lead to behavioral changes should be developed.

Key words: adolescent, health behavior, health risk behavior, glycemic control, type 1 diabetes.

Adolescence is a time of physical, emotional and social growth and development, risk taking, and vulnerability. Adolescents participate in various behaviors that may negatively affect their health, such as tobacco, alcohol, and illicit drug use; unprotected sex; violent behaviors; unhealthy eating habits; and sedentary behaviors such as watching television and playing computer games. ${ }^{1-6}$ Leatherdale et al. ${ }^{4}$ found that communication-based sedentary behaviors such as talking on the phone and instant messaging were popular among healthy adolescents and adolescents who report high levels of communication time were also more likely to report high levels of screen time. Thus, they suggested that future sedentary behaviors should be expanded to include measures of communication time. ${ }^{4}$

In the literature, studies have indicated that some lifestyle and behavioral factors represent a complex set of interconnected variables affecting the health of adolescents. For example Wilson et al. ${ }^{5}$ found that low exercise frequency and decreased vegetable and milk/dairy product

This study was presented at the 20th European Congress of the International Association for Adolescent Health, 14-17.09.2016, Prishtina as an oral presentation. 
consumption by high school students was associated with smoking, and Alikasifoglu et al. ${ }^{6}$ showed that being a bully or a victim of bullying was associated with smoking cigarette, drinking alcohol, having been drunk, playing computer games, and being sexually active. In addition, studies indicate that chronically ill adolescents may be even more likely to engage in health risk behaviors than their healthy peers, and that these behaviors may cause greater adverse health outcomes. ${ }^{7-11}$

Type 1 diabetes (T1D) is one of the most common chronic diseases of childhood and adolescence with an increasing incidence, and its long-term prognosis is fully dependent on glycemic control (GC). ${ }^{12-14}$ However, establishing good GC often becomes increasingly difficult during adolescence owing to the large number of physiological, psychological, and social changes during this period. These include increased insulin resistance, significant weight gain, and increasing independence from parents. ${ }^{15,16}$

In fact, it is well known that the management of diabetes mellitus in the pediatric and adolescent population requires increasing daily physical activity and reducing sedentary behaviors. ${ }^{17}$ However, very few studies have determined the relationship between physical activity level and GC among adolescents with T1D. ${ }^{8,9,18-20}$ Furthermore, studies on sedentary behaviors such as watching television, playing computer games or overall use of electronic media, which are considered independent risk factors for adolescent obesity and its cardiometabolic consequences, are scarce especially for adolescents with T1D. ${ }^{8,21-23}$ In addition, there is no data regarding the effects of communication time via electronic media, which has been accepted as a popular new sedentary behavior, on GC among adolescents with T1D. Furthermore, some studies have demonstrated that regular tooth brushing (which is accepted as a marker of daily selfcare and showing an association with diabetes self-efficacy) and healthy eating and drinking habits are related to better GC, whereas consumption of tobacco/alcohol/illicit drugs and disease-specific bullying are related to poor GC in adolescents with T1D. ${ }^{24-29}$

To provide appropriate counselling and treatment recommendations, healthcare providers should be aware of the health and health risk behaviors that adolescents with T1D are most likely to engage in and how these behaviors may affect their GC and other health outcomes. Thus, studies are needed to better understand the behaviors that are potential risk factors for poor GC, especially newer behaviors such as communication via electronic media.

The purpose of this study was to determine the health/health risk behaviors of a group of Turkish adolescents with T1D to determine the prevalence and explore the exact effect of these behaviors on GC.

\section{Material and Methods}

This is a cross-sectional study which was conducted to determine the relationships between GC and health and health risk behaviors in patients with T1D who were being followed up in an outpatient clinic of Pediatric Endocrinology and Diabetes of a University Hospital. Data collection was conducted between January 2014 and December 2014. The study was approved by the local ethics committee (no. 1241-2014/1208).

\section{Study design and participants}

Patients between 12-20 years of age who had been diagnosed with T1D at least 6 months ago and had no additional comorbidities were invited to the study. A self-reported questionnaire was administered to all participants, who volunteered to participate in this study, during their scheduled clinical visits by two researchers. The participants responded to the questionnaire on their own in a separate room. Written informed consents were obtained from each patient and the patient's parent. The patients and their parents were informed about the aim of the study and that the results would remain anonymous before the questionnaires were given.

The patients' age, sex, diabetes duration (at least 6 months), insulin dose used by the patient (Unit/kg per day), anthropometric data (weight in $\mathrm{kg}$ and height in $\mathrm{cm}$ ), and $\mathrm{HbAlc}$ values measured in the last 3 months were obtained from hospital records. According to the guidelines and meta-analysis results, it seems reasonable to use the HbAlc level of $8 \%$ as a maximum therapeutic goal for 
adolescents participating in an optimized management program. ${ }^{30,31}$ For that reason in this study the patients were divided into two GC groups according to their HbAlc levels; good (satisfactory) GC group consisted of the patients with $\mathrm{HbA} 1 \mathrm{c}<8 \%$, and poor (unsatisfactory) GC group consisted of the patients with $\mathrm{HbA} 1 \mathrm{c} \geq 8 \%$. The body mass index (BMI) was calculated using the following formula: $\mathrm{BMI}=$ weight $(\mathrm{kg}) /$ height $\left(\mathrm{m}^{2}\right)$. The patients were divided into normal weight, overweight, and obese groups based on the BMI, according to the criteria defined by Cole et al. ${ }^{32}$

\section{Data collection tool}

Family affluence scale and health/health risk behaviors: Behaviors such as eating behaviors, physical activity levels, tooth brushing, bullying and being bullied, involvement in a physical fight, injuries, watching television, using a computer, using electronic media for communication with friends (internet-based programs and mobile phone), smoking, alcohol drinking, and drunkenness were measured by 35 questions obtained from the "Health Behavior in Schoolaged Children" (HBSC) study international questionnaire. ${ }^{33} \mathrm{HBSC}$ is a WHO collaborative cross-national study, and has been conducted every four years over the last 30 years across 42 countries and regions across Europe and North America. HBSC is a pioneering study gaining insight into young people's well-being, health, behaviors, and their social context. The international standard questionnaire produced for every survey cycle enables the collection of common data across all participating countries, enabling the quantification of patterns of key health behaviors, health risk behaviors, health indicators, and contextual variables. ${ }^{1,33}$ Approval was not obtained from the HBSC International Coordinator because the principle investigator of the Turkish HBSC study was one of the researchers of the present study.

The items were dichotomized to describe unhealthy/risky and healthy/non-risky behaviors for statistical evaluation according to HBSC study descriptions rules. ${ }^{33}$

\section{Socioeconomic status}

Family affluence scale (FAS). A family affluence scale was used to measure socioeconomic status. The FAS included questions on whether parents of patients had their own car, van, or truck (0-2 points), their own computers (0-2 points), whether they went on a vacation with their family in the past 12 months (0-2

Table I. Comparison of Sociodemographic Characteristics, Diabetes Duration, and Body Mass Index Status Between Good and Poor Glycemic Control Groups.

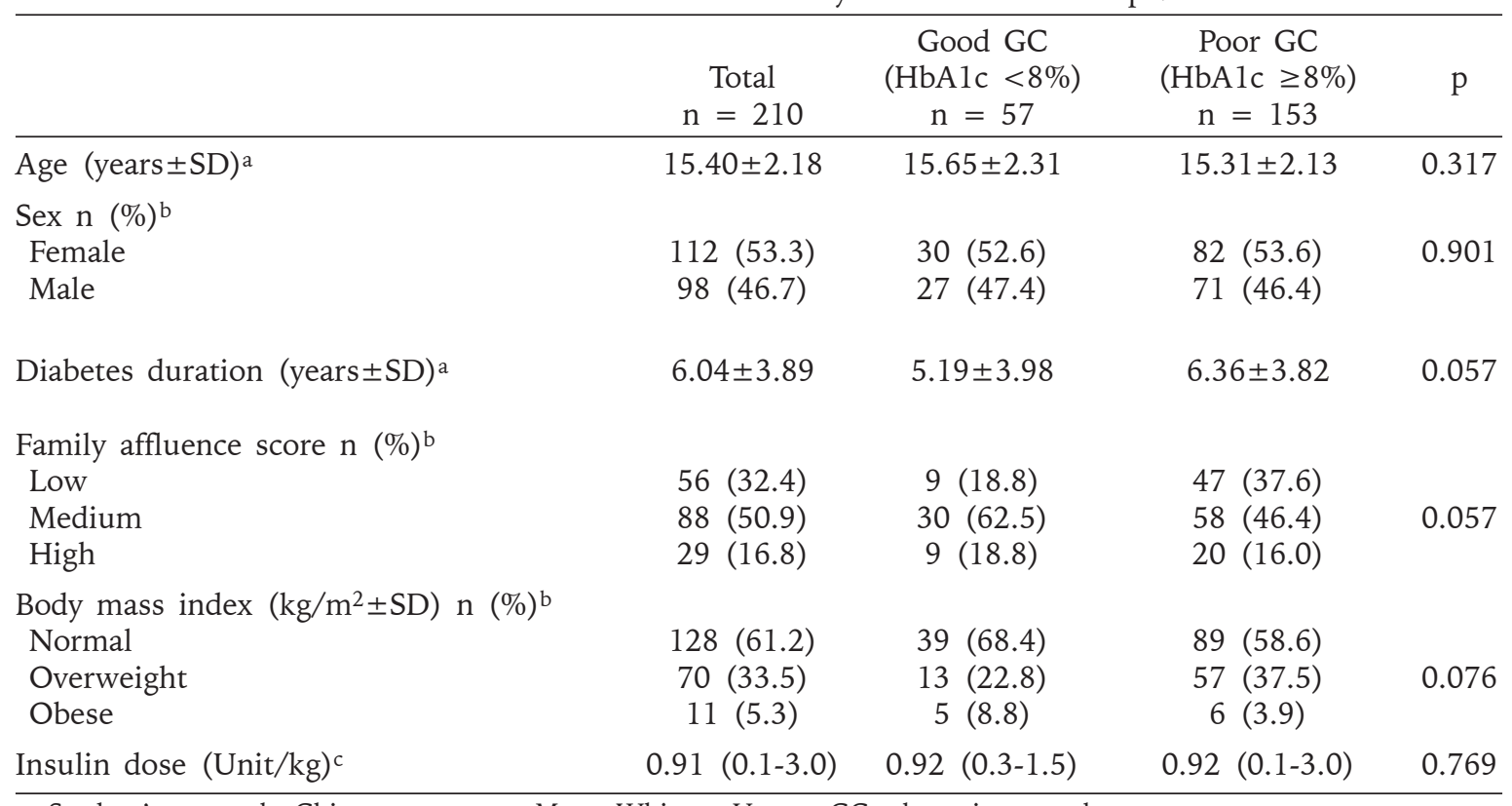

a: Student's t test, b: Chi-square test, c: Mann Whitney U test, GC: glycemic control 
points), and whether the patients had their own bedroom (0-1 point). The FAS total score, which ranged from $0-7$, was recoded into three categories: low (0-3), medium (4-5), and high (6-7).

\section{Health behaviors}

Inadequate consumption of healthy foods: Consuming fruits and vegetables less than once a day.

Frequent consumption of unhealthy food: Consuming sugar/chocolate and soft drinks 5-6 days a week or more.

Irregular tooth brushing: Tooth brushing less than once a day.

Inadequate physical activity: Engaging in physical activity less than seven days for a total of at least 60 minutes a day in the past one week.

\section{Health risk behaviors}

Being bullied: Having been bullied at school at least once in the last 1-2 months.

Bullying others: Having bullied others at school at least once in the last 1-2 months.

Getting involved in a physical fight: Having become involved in a physical fight at least once in the last 12 months.

Having been injured: Having been injured, hurt, poisoned or burned with such a severity to require treatment by a physician or healthcare worker at least once in the last 12 months.

Experimentation with smoking: Having smoked one puff or more at least once during life time.

Current smoking: Having smoked cigarettes on at least one of the preceding 30 days.

Regular smoking: Having smoked every day for the last 30 days.

Number of cigarettes smoked daily: Six or more cigarettes in a day.

Experimentation with alcohol: Having consumed an alcoholic drink at least once during life time.

Current alcohol drinking: Having consumed an alcoholic drink on at least one of the preceding 30 days

Life time drunkenness: Having been drunk at least once.

Current drunkenness: Having been drunk at least once in the last 30 days.

Table II. Health Behaviors (eating habits, tooth brushing, physical activity) in Adolescents with Type 1 Diabetes.

\begin{tabular}{|c|c|c|c|c|}
\hline Health behaviors & $\begin{array}{l}\text { Total } \\
\text { n (\%) }\end{array}$ & $\begin{array}{l}\text { Good GC } \\
(\mathrm{HbA} 1 \mathrm{c}<8 \%) \\
\mathrm{n}(\%)\end{array}$ & $\begin{array}{l}\text { Poor GC } \\
(\mathrm{HbA} 1 \mathrm{c} \geq 8 \%) \\
\mathrm{n}(\%)\end{array}$ & $\mathrm{p}$ \\
\hline \multicolumn{5}{|l|}{ Consumption of fruit } \\
\hline At least once every day & $107(51.7)$ & $30(52.6)$ & $77(51.3)$ & \multirow[t]{2}{*}{0.867} \\
\hline 5-6 days a week or less frequently & $100(48.3)$ & $27(47.4)$ & $73(48.7)$ & \\
\hline \multicolumn{5}{|l|}{ Consumption of vegetables } \\
\hline At least once every day & $75(35.7)$ & $21(36.8)$ & $54(35.3)$ & \multirow[t]{2}{*}{0.835} \\
\hline 5-6 days a week or less frequently & $135(64.3)$ & $36(63.2)$ & $99(64.7)$ & \\
\hline \multicolumn{5}{|l|}{ Consumption of sugar or chocolate } \\
\hline $2-4$ days a week or less frequently & $162(77.1)$ & $47(82.5)$ & $115(75.2)$ & \multirow{2}{*}{0.263} \\
\hline 5 days a week or more frequently & $48(22.9)$ & $10(17.5)$ & $38(24.8)$ & \\
\hline \multicolumn{5}{|l|}{ Consumption of soft drink } \\
\hline 2-4 days a week or less frequently & $187(89.0)$ & $53(93.0)$ & $134(87.6)$ & \multirow[t]{2}{*}{0.265} \\
\hline 5 days a week or more frequently & $23(11.0)$ & $4(7.0)$ & $19(12.4)$ & \\
\hline \multicolumn{5}{|l|}{ Tooth brushing } \\
\hline At least once a day & $176(83.8)$ & $49(86.0)$ & $127(83.0)$ & \multirow[t]{2}{*}{0.605} \\
\hline Less than once a day or not & $34(16.2)$ & $8(14.0)$ & $26(17.0)$ & \\
\hline \multicolumn{5}{|l|}{ Physical activity } \\
\hline Adequate & $33(16.0)$ & $4(7.0)$ & $29(19.5)$ & \multirow[t]{2}{*}{0.029} \\
\hline Inadequate & $173(84.0)$ & $53(93.0)$ & $120(80.5)$ & \\
\hline
\end{tabular}

$\mathrm{n}$ numbers differ because not all patients answered equal numbers of questions.

GC: Glycemic control, HbAlc: Hemoglobin Alc. Significance $p<0.05$ 


\section{Electronic media use}

Watching television for long periods of time (including video and $D V D$ ): Watching television for $\geq$ two hours per day by considering the weighted mean values of the periods of watching TV on weekdays and weekends.

Playing computer games (including game consoles) for long periods of time: Playing games for 2 hours or more per day by considering the weighted mean values of the periods of playing on weekdays and weekends.

Frequent communication with friends via electronic media (talking on mobile phones or internet-based programs such as FaceTime and Skype; sending text messages from the mobile phone; instant messaging using BBM, WhatsApp, Facebook Chat; and using programs including Facebook, Twitter, Myspace, Instagram, and YouTube; and playing internet-based games using devices such as Xbox): Using at least one of these tools every day to communicate with friends.

Frequent communication with friends via email: Using email every day to communicate with friends.

Computer use for homework for long period of time: Using a computer for homework $\geq 2$ hours per day, calculated by taking the weighted mean of the time periods of use on weekdays and weekends.

\section{Statistical analysis}

SPSS version 15 (Chicago, IL, USA) was used for statistical analysis. The Student's t test was used to compare continuous variables (age, insulin doses, diabetes duration) between two GC groups (good and poor GC). The chisquare test was used to compare the categorical variables (behaviors, FAS score groups and BMI groups) and Mann Whitney-U test was used to compare insulin doses (Unit/kg per day) between GC groups. In addition, descriptive statistics were used to give frequencies, percentages, and standard deviations.

The logistic regression model was applied using a backward stepwise method, using GC status as a dependent variable, and sex, BMI, and FAS score as control variables. The variables with a significance level of $\mathrm{p} \leq 0.2$ in the chi-square test was included as independent variables in the analysis. 34 While the $p$ value of the comparison of insulin doses between GC groups was $>0.2$, it was not included in the logistic regression analysis. Sex was included in the logistic regression analysis as a control variable due to its known effects on health/ health risk behaviors. A p value of $<0.05$ was considered significant.

\section{Results}

A total of 330 patients with T1D, aged between $12-20$ years, were admitted to the pediatric endocrinology clinic in the period the study. The questionnaire was not applied to 7 adolescents who were intellectually challenged, 12 patients refused to participate in the study, and 29 adolescents could not be contacted on the day they arrived at the clinic due to technical reasons. Thus, we applied the questionnaires to a total of 282 adolescents. Eleven questionnaires were excluded because more than half of the questions had not been answered, 19 were excluded because of no $\mathrm{HbAlc}$ data in the last three months, and 42 were excluded due to additional comorbidity/ies (subject loss $=8.8 \%$ ). A total of 210 adolescents were included in the final statistical evaluation.

Of the adolescents, $53 \%$ were female ( $n=$ $112)$ and $47 \%$ were male $(n=98)$. The mean age was $15.40 \pm 2.18$ (range, 12-20) years. The mean diabetes duration was $6.04 \pm 3.89$ (range, $0.5-17)$ years. The mean BMI $\left(\mathrm{kg} / \mathrm{m}^{2}\right)$ was $22.67 \pm 3.41$ (range, 15.87-33.85) $\mathrm{kg} / \mathrm{m}^{2}$. There were no differences between good and poor GC groups in terms of mean age, diabetes duration, FAS scores, insulin doses (Unit/kg per day) and BMI (Table I).

Of the patients, $84 \%$ were reported that they were inadequately physically active. The patients in the poor GC group were more adequately physically active than those in the good GC group $(p=0.029)$. Table II presents the distribution of other health behaviors among the groups. Frequency of health risk behaviors were similar in the poor and good GC group (Table III).

It was found that $83.3 \%$ of the patients communicated with their friends every day via electronic media, including BBM, WhatsApp, and Facebook Chat. Frequent communication with friends via electronic media was significantly higher in the poor GC group than in the good GC group ( $p=0.022)$. The patients in the good GC group reported that they use the computer 
Table III. Health Risk Behaviors (bullying, fighting, injury, smoking, drinking alcohol) in Adolescents with Type 1 Diabetes.

\begin{tabular}{|c|c|c|c|c|}
\hline Health risk behaviors & $\begin{array}{l}\text { Total } \\
\text { n (\%) }\end{array}$ & $\begin{array}{l}\text { Good GC } \\
(\text { HbA1c }<8 \%) \\
\text { n }(\%)\end{array}$ & $\begin{array}{l}\text { Poor GC } \\
(\mathrm{HbA} 1 \mathrm{c} \geq 8 \%) \\
\mathrm{n}(\%)\end{array}$ & $\mathrm{p}$ \\
\hline $\begin{array}{l}\text { Being bullied } \\
\text { Never } \\
\text { At least once }\end{array}$ & $\begin{array}{l}148(71.5) \\
59(28.5)\end{array}$ & $\begin{array}{ll}38 & (67.9) \\
18 & (32.1)\end{array}$ & $\begin{array}{l}110(72.8) \\
41(27.2)\end{array}$ & 0.480 \\
\hline $\begin{array}{l}\text { Bullying } \\
\text { Never } \\
\text { At least once }\end{array}$ & $\begin{array}{l}154(74.8) \\
52(25.2)\end{array}$ & $\begin{array}{ll}40 & (72.7) \\
15 & (27.3)\end{array}$ & $\begin{array}{l}114(75.5) \\
37(24.5)\end{array}$ & 0.686 \\
\hline $\begin{array}{l}\text { Getting involved in a physical fight } \\
\text { Never } \\
\text { At least once }\end{array}$ & $\begin{array}{l}137(65.6) \\
72(34.4)\end{array}$ & $\begin{array}{ll}36 & (64.3) \\
20 & (35.7)\end{array}$ & $\begin{array}{l}101(66.0) \\
52(34.0)\end{array}$ & 0.816 \\
\hline $\begin{array}{l}\text { Having been injured } \\
\text { Never } \\
\text { At least once }\end{array}$ & $\begin{array}{l}155(74.2) \\
54(25.8)\end{array}$ & $\begin{array}{ll}46 & (80.7) \\
11 & (19.3)\end{array}$ & $\begin{array}{l}109(71.7) \\
43(28.3)\end{array}$ & 0.186 \\
\hline $\begin{array}{l}\text { Experimentation with smoking } \\
\text { Never } \\
\text { At least once during life time }\end{array}$ & $\begin{array}{l}175(84.1) \\
33(15.9)\end{array}$ & $\begin{array}{l}50(89.3) \\
6(10.7)\end{array}$ & $\begin{array}{l}125(82.2) \\
27(17.8)\end{array}$ & 0.217 \\
\hline $\begin{array}{l}\text { Current smoking } \\
\text { Never } \\
\text { At least once in the last } 30 \text { days }\end{array}$ & $\begin{array}{l}189(90.9) \\
19(9.1)\end{array}$ & $\begin{array}{l}54(96.4) \\
2(3.6)\end{array}$ & $\begin{array}{l}135(88.8) \\
17(11.2)\end{array}$ & 0.091 \\
\hline $\begin{array}{l}\text { Regular smoking } \\
\text { No } \\
\text { Yes }\end{array}$ & $\begin{array}{l}199(96.1) \\
8(3.9)\end{array}$ & $\begin{array}{l}54(96.4) \\
2(3.6)\end{array}$ & $\begin{array}{l}145(96.0) \\
6(4.0)\end{array}$ & 0.531 \\
\hline $\begin{array}{l}\text { Number of cigarettes smoked daily } \\
<6 \text { per day } \\
\geq 6 \text { per day }\end{array}$ & $\begin{array}{l}204(98.1) \\
4(1.9)\end{array}$ & $\begin{array}{l}55(98.2) \\
1(1.8)\end{array}$ & $\begin{array}{l}149(98.0) \\
3(2.0)\end{array}$ & 0.930 \\
\hline $\begin{array}{l}\text { Experimentation with alcohol } \\
\text { Never } \\
\text { At least once during life time }\end{array}$ & $\begin{array}{l}157(76.2) \\
49(23.8)\end{array}$ & $\begin{array}{ll}43 & (76.8) \\
13 & (23.2)\end{array}$ & $\begin{array}{l}114(76.0) \\
36(24.0)\end{array}$ & 0.930 \\
\hline $\begin{array}{l}\text { Current alcohol drinking } \\
\text { Never } \\
\text { At least once in the last } 30 \text { days }\end{array}$ & $\begin{array}{l}186(89.9) \\
21(10.1)\end{array}$ & $\begin{array}{l}53(94.6) \\
3(5.4)\end{array}$ & $\begin{array}{l}133(88.1) \\
18(11.9)\end{array}$ & 0.165 \\
\hline $\begin{array}{l}\text { Drunkenness (during life time) } \\
\text { Never } \\
\text { At least once }\end{array}$ & $\begin{array}{l}193(93.2) \\
14(6.8)\end{array}$ & $\begin{array}{l}52(94.5) \\
3(5.5)\end{array}$ & $\begin{array}{l}141(92.8) \\
11(7.2)\end{array}$ & 0.652 \\
\hline $\begin{array}{l}\text { Drunkenness (in the last } 30 \text { days) } \\
\text { Never } \\
\text { At least once }\end{array}$ & $\begin{array}{l}205(98.6) \\
3(1.4)\end{array}$ & $\begin{array}{l}56(100.0) \\
0(0.0)\end{array}$ & $\begin{array}{l}149(98.0) \\
3(2.0)\end{array}$ & 0.290 \\
\hline
\end{tabular}

$\mathrm{n}$ numbers show difference because not all patients answered equal numbers of questions.

GC: Glycemic control, HbA1c: Hemoglobin A1c

Significance $\mathrm{p}<0.05$

for homework for a longer period of time $(\geq 2$ hours/day) than those in the poor GC group $(\mathrm{p}=0.010)$. Table IV presents a comparison of communication with friends via electronic media, watching television, playing computer games, and computer use for homework between the poor and good GC groups.

In the backward stepwise logistic regression analysis, being overweight and frequent communication with friends via electronic media were found to be the risk factors for poor GC, whereas using a computer for homework for long period of time ( $\geq 2$ hours/day) was found to be a protective factor for poor GC (Table V).

Discussion 
Table IV. Electronic Media Use (watching television, playing computer games, using computer for homework, communication with friends) in Adolescents with Type 1 Diabetes.

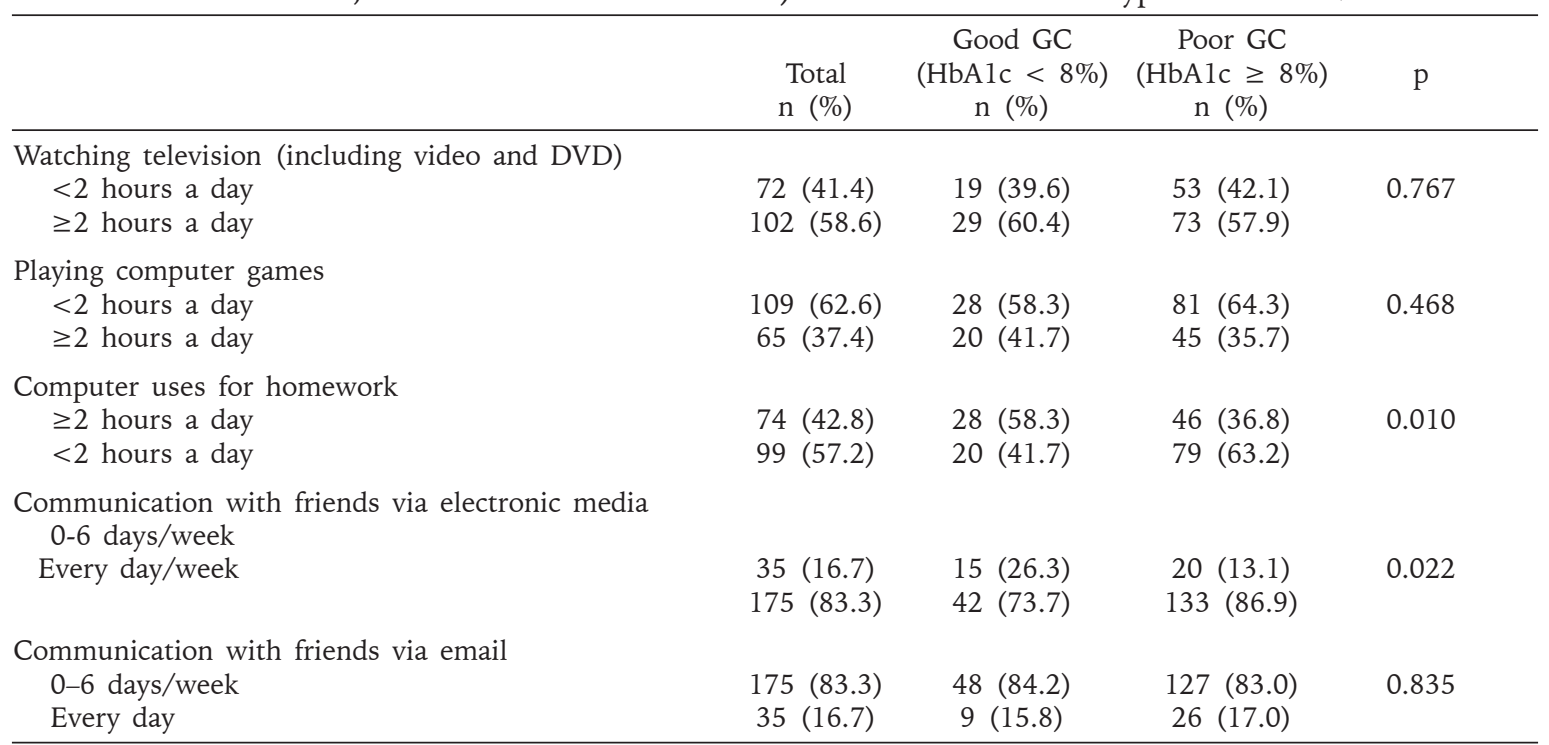

$\mathrm{n}$ numbers show difference because not all patients answered equal number of questions.

GC: Glycemic control, HbAlc: Hemoglobin Alc. Significance $p<0.05$

Lifestyle and behaviors are important modifiable patient-associated factors for optimizing health among adolescents with T1D. Here, in a clinical sample of adolescents with T1D, we found that being overweight and frequent communication with friends via electronic media were independent risk factors associated with poor GC, whereas computer use for homework for long period of time ( $\geq 2$ hours/ day) was found to be an independent protective factor associated with poor GC.

Cavdar et al. ${ }^{2}$ also used the HBSC survey questionnaire in their study, which was conducted among high school students. When compared with their results we can say that our study population were more likely to consume fruits $(51.7 \% / 36.2 \%)$ and vegetables $(35.7 \% / 14.1 \%)$, exhibit adequate physical activity $(16 \% / 10 \%)$, and be less likely to smoke cigarettes (current smoking 9.1\%/26.3\%), drink alcohol (current drinking 10.1\%/38.4\%) and soft drinks $(11 \% / 18 \%)$, and consume sugar/ sweets $(22.9 \% / 31.3 \%)$ compared to healthy Turkish adolescents. ${ }^{2}$ However, the frequency of watching television (58.6\%/59.9\%) and taking part in bullying behaviors (bullying others $25.2 \% / 29.9 \%$ ) were almost similar both in our study and data reported in the previous study. ${ }^{2}$ The results of the present study contradict the results of some of the previous studies, indicating that chronically ill adolescents may be more likely to engage in health risk behaviors than their healthy peers. ${ }^{7,8}$ These results could be partly explained by the intervention implemented during routine clinical visits to all patients with diabetes and/ or parental monitoring and involvement in medical treatment. Independence from parents during adolescence has been reported to have a negative impact on GC in adolescents with T1D. ${ }^{16,18}$

A large majority of this population of adolescents with T1D failed to meet the current recommendations for physical activity ${ }^{17}$, approximately half of the subjects failed to meet current recommendations for healthy nutrition ${ }^{35}$, and the majority of them failed to meet current recommendations for electronic media use (including television watching, computer gaming, and communication via electronic media) ${ }^{36}$, which are accepted important disease-related health behaviors that affect the GC. $8,27,28,37$ These behaviors might be a marker of unhealthy lifestyle, because some studies have shown that these behaviors are interconnected. ${ }^{27}$ Thus, it is necessary to reevaluate and enhance our intervention strategies to cover electronic media communication, a new popular sedentary behavior, to optimize the benefits of the 
programs and to explore in detail the factors associated with these behaviors in adolescents with T1D.

In addition, $38.8 \%$ of the individuals in this study were overweight or obese. In the logistic regression analysis, being overweight was found to be a risk factor for poor GC, whereas being obese was not. This may be because there were too few obese adolescents in this study. Nowadays, overweight/obesity is highly prevalent in children with T1D and has been shown to be associated with increased insulin requirements, poor GC, and atherosclerosis. ${ }^{38,39}$ Thus, interventions for overweight/obese patients should be planned to promote healthy eating behaviors and physical activity in order to reduce the chances of overweight and obesity.

Univariate analysis in the present study revealed that adolescents with poor GC were more likely to be physically active than those with good GC, although we did not find any independent association between adequate physical activity and poor GC in logistic regression analysis. Some studies also showed that physical activity level was not associated with GC. ${ }^{40}$ Despite this, other studies have suggested that there is a relationship between poor GC and less physical activity. $8,9,18-20$ This contradictory result may be related to more time available for these patients and more effort given to these patients to promote physical activity during their regularly scheduled clinical visit.

In the present study, results of the logistic regression analysis revealed an independent association between frequent communication with friends via electronic media and poor GC. We could not find any study that investigated the effect of this behavior on GC in adolescents with T1D. However, more television watching and more time spent on the computer in children and adolescents with T1D have been associated with poorer GC and more adverse lipid profiles in both cross-sectional and longitudinal studies. ${ }^{21,23,41}$ The results of this study suggest that when intervention modalities to minimize sedentary behaviors and promote healthy eating and physical activity are developed, healthcare staff need to be aware of the potentially harmful effects of frequent electronic media use and implement strategies to help patients to moderate their usage of electronic media.

Computer use for homework for long period of time ( $\geq 2$ hours/day) was found to be a protective factor for poor GC in our study. Aman et al. $^{23}$ also reported that adolescents who used computers for homework over extended periods had more favorable HbAlc values, and they related this result to personality characteristics, particularly conscientiousness. There is increasing evidence that conscientiousness is an important predictor of health behavior and also contributes to better adherence to medical recommendations. ${ }^{39,42}$ In the context of chronic illness, conscientiousness has been associated with better self-care in adolescents and young adults with T1D. ${ }^{39,43}$ A recent research has linked low conscientiousness to the mismanagement of GC in patients with T1D. ${ }^{43}$ The result of our study and that of

Table V. Backward Stepwise Logistic Regression Analysis: Factors Independently Associated With Poor Glycemic Control.

\begin{tabular}{|c|c|c|c|c|}
\hline & B & Odds ratio & $\begin{array}{l}\text { 95\% CI } \\
\text { (Lower-Upper) }\end{array}$ & $\mathrm{p}$ \\
\hline Being overweight & 0.971 & 2.642 & $1.121-6.226$ & 0.026 \\
\hline Being obese & -1.350 & 0.259 & $0.057-1.188$ & 0.082 \\
\hline Alcohol drinking at least once in the last 30 days & 1.332 & 3.788 & $0.851-16.865$ & 0.080 \\
\hline $\begin{array}{l}\text { Computer use for homework for long period of time } \\
(\geq 2 \text { hours/day) }\end{array}$ & -1.218 & 0.296 & $0.133-0.659$ & 0.003 \\
\hline $\begin{array}{l}\text { Frequent communication with friends via electronic } \\
\text { media }\end{array}$ & 1.485 & 4.415 & $1.715-11.369$ & 0.002 \\
\hline
\end{tabular}

Physical activity, having been injured (in the last 12 months), communication with friends via electronic media, current smoking, current alcohol drinking and computer use for homework were included in the analysis as independent variables and sex, body mass index, and family affluence scale score were included in the analysis as control variables. Significance $\mathrm{p}<0.05$ 
Aman et al. ${ }^{23}$ invites the question whether time spent on computers for homework could really be a marker of personality traits, especially conscientiousness, which could be directly modified through intervention. Further longitudinal studies are needed to answer this question.

Our study has some limitations. First, it was conducted in a single center, so the results cannot be generalized. Second, health behaviors were self-reported and could have been affected by poor recall, although the HBSC has been used in many countries and previous studies have reported the reliability and validity of this questionnaire. Third, although the number of patients included in the study was sufficient, the fact that only few patients reported some health risk behaviors (for example, frequent consumption of unhealthy food, current alcohol drinking and getting drunk) might have led to the finding that there was no relationship between these behaviors and GC.

In the literature, many studies have investigated sedentary behaviors of patients with T1D, but there is no information about the relationship between communication via electronic media, especially instant messaging, which is a recent and one of the most popular ways of communication, and GC among adolescents with T1D. Our study is the first to illustrate the effect of frequent communication via electronic media on GC among adolescents with T1D. This is also the first study conducted on adolescents with T1D on this subject in Turkey. We believe our study has important results in this respect.

In conclusion, provision of good GC in adolescents with T1D is closely related with health behaviors, especially less electronic media use for communication and computer use for homework for long period of time ( $\geq 2$ hour/day), which might be considered as a sense of responsibility. Screening adolescents and educating them regarding health behaviors at each outpatient clinic visit, and giving them health responsibilities should become an integral part of comprehensive pediatric care for adolescents with T1D. Furthermore, intervention programs that initiate behavioral changes should be developed.

\section{Acknowledgments}

The authors thank the adolescents and their families who helped to realize this study, David F. Chapman for proofreading and editing the manuscript, and also thanks to all personel working in the Department of Pediatric Endocrinology and Diabetes for their assistance.

\section{REFERENCES}

1. Inchley J, Currie D, Young T, Samdal O, et al. Growing Up Unequal: Gender and Socioeconomic Differences in Young People's Health and Well-being. Health Behaviour in School-aged Children (HBSC) study: international report from the 2013/2014 survey. Health Policy for Children and Adolescents, No. 7 Copenhagen, WHO Regional Office for Europe, 2016.

2. Çavdar S, Sümer EÇ, Eliaçık K, et al. Health behaviors in high school students in İzmir, Turkey. Turk Pediatri Ars 2016; 51: 22-34.

3. Erguder T, Çakır B, Aslan D, Warren CW, Jones NR, Asma S. Evaluation of the use of Global Youth Tobacco Survey (GYTS) data for developing evidence-based tobacco control policies in Turkey. BMC Public Health 2008; 8(Suppl 1): S4.

4. Leatherdale ST. Factors associated with communicationbased sedentary behaviours among youth: are talking on the phone, texting, and instant messaging new sedentary behaviors to be concerned about? J Adolesc Health 2010; 47: 315-318.

5. Wilson DB, Smith BN, Speizer IS, et al. Differences in food intake and exercise by smoking status in adolescents. Prev Med 2005; 40: 872-879.

6. Alikasifoglu M, Erginoz E, Ercan O, Uysal O, AlbayrakKaymak D. Bullying behaviours and psychosocial health: results from a cross-sectional survey among high school students in Istanbul, Turkey. Eur J Pediatr 2007; 166: 1253-1260.

7. Suris JC, Michaud PA, Akre C, Sawyer SM. Health risk behaviors in adolescents with chronic conditions. Pediatrics 2008; 122: 1113-1118.

8. Lobelo F, Liese AD, Liu J, et al. Physical activity and electronic media use in the SEARCH for diabetes in youth case-control study. Pediatrics 2010; 125: e1364-e1371.

9. Valerio G, Spagnuolo MI, Lombardi F, Spadaro R, Siano M, Franzese A. Physical activity and sports participation in children and adolescents with type 1 diabetes mellitus. Nutr Metab Cardiovasc Dis 2007; 17: 376-382.

10. Maggio AB, Hofer MF, Martin XE, Marchand LM, Beghetti M, Farpour-Lambert NJ. Reduced physical activity level and cardiorespiratory fitness in children with chronic diseases. Eur J Pediatr 2010; 169: 11871193.

11. Kummer S, StahlS-Pehe A, Castillo K, et al. Health behaviour in children and adolescents with type 1 diabetes compared to a representative reference population. PLoS One 2014; 9: e112083.

12. Orr DP. Diabetes mellitus. In: Neinstein LS, Gordon CM, Katzman DK, Rosen DS, Woods ER (eds). Adolescent 
Health Care 'A Practical Guide' (5th ed) Philadelphia: Lippincott Williams \& Wilkins, 2008: 170-179.

13. Onkamo P, Väänänen $S$, Karvonen $M$, Tuomilehto J. Worldwide increase in incidence of Type 1 diabetes the analysis of the data on published incidence trends. Diabetologia 1999; 42: 1395-1403.

14. Karvonen M, Pitkaniemi J, Tuomilehto J. The onset of type 1 diabetes in Finnish children has become younger. The Finnish Childhood Diabetes Registry Group. Diabetes Care 1999; 22: 1066-1070.

15. Cho YH, Craig ME, Donaghue KC. Puberty as an accelerator for diabetes complications. Pediatr Diabetes 2014; 15: 18-26.

16. Anderson BJ, Vangsness L, Connell A, Butler D, GoebelFabbri A, Laffel LM. Family conflict, adherence, and glycaemic control in youth with short duration Type 1 diabetes. Diabet Med 2002; 19: 635-642.

17. Colberg SR, Sigal RJ, Yardley JE, et al. Physical Activity/ Exercise and Diabetes: A Position Statement of the American Diabetes Association. Diabetes Care 2016; 39: 2065-2079.

18. Jasser SS, Yates H, Dumser S, Whittemore R. Risky business: risk behaviors in adolescents with type 1 diabetes. Diabetes Educ 2011; 37: 756-764.

19. Roberts L, Jones TW, Fournier PA. Exercise training and glycemic control in adolescents with poorly controlled type 1 diabetes mellitus. J Pediatr Endocrinol Metab 2002; 15: 621-627.

20. Beraki A, Magnuson A, Sarnblad S, Aman J, Samuelsson $\mathrm{U}$. Increase in physical activityis associated with lower $\mathrm{HbAlc}$ levels in children and adolescents with type 1diabetes: results from a cross-sectional study based on the Swedish pediatric diabetes quality registry (SWEDIAKIDS). Diabetes Res Clin Pract 2014; 119125.

21. Margeirsdottir HD, Larsen JR, Brunborg C, Sandvik L, Dahl-Jørqensen K; Norwegian Study Group for Childhood Diabetes. Strong association between time watching television and blood glucose control in children and adolescents with type 1 diabetes. Diabetes Care 2007; 30: 1567-1570.

22. Galler A, Lindau M, Ernert A, Thalemann R, Raile K. Associations between media consumption habits, physical activity, socioeconomic status, and glycemic control in children, adolescents, and young adults with type 1 diabetes. Diabetes Care 2011; 34: 2356-2359.

23. Âman J, Skinner TC, De Beaufort CE, Swift PG, Aanstoot HJ, Cameron F; Hvidoere Study Group on Childhood Diabetes. Associations between physical activity, sedentary behaviour and glycemic control in a large cohort of adolescents with type 1 diabetes: the Hvidoere Study Group on Childhood Diabetes. Pediatr Diabetes 2009; 10: 234-239.

24. Syrjälä AM, Kneckt MC, Knuuttila ML. Dental selfefficacy as a determinant to oral health behaviour, oral hygiene and HbA1c level among diabetic patients. J Clin Periodontol. 1999; 26: 616-621.

25. Kneckt MC, Keinänen-Kiukaanniemi SM, Knuuttila ML, Syrjälä AM. Self-esteem as a characteristic of adherence to diabetes and dental self-care regimens. J Clin Periodontol 2001; 28: 175-180.
26. Reynolds K, Liese AD, Anderson AM, et al. Prevalence of tobacco use and association between cardiometabolic risk factors and cigarette smoking in youth with type 1 or type 2 diabetes mellitus. J Pediatr 2011; 158: 594-601.

27. Bortsov A, Liese AD, Bell RA, et al. Correlates of dietary intake in youth with diabetes: results from the SEARCH for diabetes in youth study. J Nutr Educ Behav 2011; 43: 123-129.

28. Bortsov AV, Liese AD, Bell RA, et al. Sugar-sweetened and diet beverage consumption is associated with cardiovascular risk factor profile in youth with type 1 diabetes. Acta Diabetol 2011; 48: 275-282.

29. Storch EA, Heidgerken AD, Geffken GR, et al. Bullying, regimen self-management, and metabolic control in youth with type I diabetes. J Pediatr 2006; 148: 784787.

30. Escobar O, Drash AL, Becker DJ. Management of the child with type 1 diabetes. In: Lifshitz F (eds). Pediatric Endocrinology. Vol 1. Informa Healthcare, New York, NY, USA, 2007; 101-124.

31. Rewers MJ, Pillay K, de Beaufort C, et al; International Society for Pediatric and Adolescent Diabetes. ISPAD Clinical Practice Consensus Guidelines 2014. Assessment and monitoring of glycemic control in children and adolescents with diabetes. Pediatric Diabetes 2014; 15 (Suppl 1):102-114

32. Cole TJ, Flegal KM, Nicholls D, Jackson AA. Body mass index cut offs to define thinness in children and adolescents: international survey. BMJ 2007; 335: 194.

33. Currie C, Zanotti C, Morgan A, et al. Social determinants of health and well-being among young people. Health Behaviour in School-Aged Children (HBSC) Study: International Report From the 2009/2010 Survey. Copenhagen: WHO Regional Office for Europe, (Health Policy for Children and Adolescents, No. 6); 2012.

34. Hosmer DW, Lemeshow S. Application of logistic regression with different sampling model. In: Applied logistic regression (2nd ed) New York: John Wiley \& Sons, Inc., 2000: 203-222.

35. American Diabetes Association, Bantle JP, Wylie-Rosett $\mathrm{J}$, Albright AL, et al. Nutrition recommendations and interventions for diabetes: a position statement of the American Diabetes Association. Diabetes Care 2008; 31(Suppl 1): S61-S78.

36. American Academy of Pediatrics. Children, adolescents and television. Pediatrics 2001; 107: 423-426.

37. Buse JB, Ginsberg HN, Bakris GL, et al; American Heart Association; American Diabetes Association. Primary prevention of cardiovascular diseases in people with diabetes mellitus: a scientific statement from the American Heart Association and the American Diabetes Association. Circulation 2007; 115: 114-126.

38. Chillaron JJ, Flores Le-Roux JA, Benaiges D, PedroBotet J. Type 1 diabetes, metabolic syndrome and cardiovascular risk. Metabolism 2014; 63: 181-187.

39. van Vliet M, Van der Heyden JC, Diamant $M$, et al. Overweight is highly prevalent in children with type 1 diabetes and associates with cardiometabolic risk. J Pediatr 2010; 156: 923-929. 
40. Skinner TC, Hampson SE, Fife-Schaw C. Personality, personal model beliefs, and self-care in adolescents and young adults with Type 1 diabetes. Health Psychol 2002; 21: 61-70.

41. Li C, Beech B, Crume T, et al. Longitudinal association between television watching and computer use and risk markers in diabetes in the SEARCH for Diabetes in Youth Study. Pediatr Diabetes 2015; 16: 382-391.
42. Bogg T, Roberts BW. The case for conscientiousness: evidence and implications for a personality trait marker of health and longevity. Ann Behav Med 2013; 45: 278-288.

43. Vollrath ME, Landolt MA, Gnehm HE, Laimbacher J, Sennhauser FH. Child and parental personality are associated with glycaemic control in Type 1 diabetes. Diabet Med 2007; 24: 1028-1033. 